\title{
Effect of the Communication Skill Training of Mothers Using Multimedia on the Anxiety Levels of Primary School Students
}

\author{
Ashraf Mohamadi' ${ }^{1}$ Zahra Hajiamini ${ }^{2 *}$, Abbas Ebadi ${ }^{1}$, Ali Fathi-Ashtiani ${ }^{3}$, Matin Ali-Asgari ${ }^{4}$, \\ Afsane Mohamadi ${ }^{5}$ \\ ${ }^{1}$ Nursing Department, Baqiyatallah University of Medical Sciences, Tehran, Iran \\ ${ }^{2}$ Behavioral Sciences Research Center, Nursing Department, Baqiyatallah University of Medical Sciences, \\ Tehran, Iran \\ ${ }^{3}$ Behavioral Sciences Research Center, Department of Psychology, Baqiyatallah University of Medical Sciences, \\ Tehran, Iran \\ ${ }^{4}$ Medicine Department, Iran University of Medical Sciences, Tehran, Iran \\ ${ }^{5}$ Nursing Department, Tarbiat Modaress University of Medical Sciences, Tehran, Iran \\ Email: ${ }^{*}$ z hajiamini@hotmail.com
}

Received 16 April 2014; revised 13 May 2014; accepted 11 June 2014

Copyright (C) 2014 by authors and Scientific Research Publishing Inc.

This work is licensed under the Creative Commons Attribution International License (CC BY). http://creativecommons.org/licenses/by/4.0/

(c) (i) Open Access

\section{Abstract}

Anxiety disorders are among the most common psychological disorders in children. Considering the effects of the relationship between parents (especially mothers) and children on the mental health of children, we conducted this study to evaluate the effect of communication skills training of mothers by multimedia software. This clinical trial was conducted on 109 first-grade students in one of the zones in Tehran. For data collection, we used the School Anxiety Scale-Teacher Report and the Queendom Communication Skill Test to assess mothers' communication skills. Students' anxiety levels and mothers' communication skills were assessed (in both groups before and after of intervention). Then students were randomly assigned to two groups: case and control. The case group received multimedia $\mathrm{CD}$ for communication skills training during 2 months. The total prevalence rate of anxiety in students before intervention was $16.1 \%$. It significantly decreased in the multimedia group after intervention $(P<0.05)$, as shown by the Wilcoxon test, but the difference was not significant in the control group. Furthermore, the mean (SD) score of the communication skills of mothers was $(114 \pm 9.8)$ before intervention, which significantly increased in the case group $(P<0.05)$. Communication skills training for mothers using multimedia software programs is an effective way to reduce children's anxiety. Therefore, this kind of training should be provided to parents because it is inexpensive and can be used frequently.

"Corresponding author.

How to cite this paper: Mohamadi, A., Hajiamini, Z., Ebadi, A., Fathi-Ashtiani, A., Ali-Asgari, M., \& Mohamadi, A. (2014). Effect of the Communication Skill Training of Mothers Using Multimedia on the Anxiety Levels of Primary School Students. Psychology, 5, 950-955. http://dx.doi.org/10.4236/psych.2014.58105 


\section{Keywords}

\section{Anxiety, Student, School Anxiety Scale-Teacher Report (SAS-TR), Multimedia Software}

\section{Introduction}

Children are the future assets of a country. They are vital for a country's survival. They grow up in a family and then in a society, where they get familiar with and are influenced by their community (Hope et al., 2004). Schools are an important factor in providing or impeding students' mental health (Khalylan et al., 2000).

Anxiety disorders are among the most prevalent and disabling psychiatric disorders during childhood and adolescence (Cartwright-Hatton et al., 2006; Waters et al., 2008). The age of onset for anxiety disorders is lower than that for other psychiatric disorders (Broeren \& Muris, 2008; Kessler et al., 2005), with an estimated prevalence rate of 3.5\% to 17\% (Cartwright-Hatton et al., 2006; Craske et al., 2008). Most anxieties and fears at mild to moderate levels are essential for the development and training of children (Muris, 2007; Li \& Lopez, 2007; Whiteside \& Brown, 2008), but severe anxiety interferes with children's normal functioning. If left untreated, they can continue into adolescence and adulthood (Muris et al., 2003; Kendall et al., 2007). In addition, childhood anxiety disorders are associated with the high risk of anxiety disorders, depression, and drug abuse in adulthood (Brückl et al., 2007; Dubi \& Schneider, 2009).

Mothers are the most valuable source of comfort, love, and prosperity for the family. In fact, mothers are the backbone of children's personality (Ghaemi, 2007). Parents of anxious children probably experience anxiety themselves in a way that they overprotect their children or over interfere in their affairs (Waters et al., 2008). Studies show that the risk of anxiety in children whose parents are anxious is 3.5 times as much as healthy controls (Gar \& Hudson, 2008).

Elevating communication skills as a part of life skills is believed to improve mental health. These abilities help individuals to effectively confront different situations, to have a positive and adaptive relationship with other people, and to furnish themselves with mental health. The role of education in human life is undeniable because proper education leads to learning science and technology and having a prosperous life (Seyyed et al., 2010) and results in behavior change (Dehkordi et al., 2008). Education can be applied in different ways, including electronically through multimedia software programs. Multimedia education can increase learning by $25 \%$ as compared with traditional classes. In some cases, electronic education per se can meet educational needs. Such an increasing demand for education has led educational centers and companies to develop appropriate software programs (Zolfaghari et al., 2007; Pryor \& Bitter, 2008). Studies of Pryor and Bitter (2008) on teachers' on-the-job training courses, Atashzadeh et al. (2006) on nursing students' learning, and Mladenovski and Kieser (2008) on patients' knowledge score before operation showed that multimedia education is more effective than other methods.

Considering the fact that a variety of media other than books to attain educational and research goals exist, it is necessary to evaluate them more extensively (Abadi \& Tavakoli, 2005). Therefore, we aimed to determine the effect of the communication skills training of mothers on the anxiety levels of first-grade students because anxiety is prevalent in children. Anxiety disorders affect children's future personality and society, and education through multimedia has a more permanent effect.

\section{Methodology}

Participants: This quasi-experimental, clinical trial enrolled 109 first-grade elementary students (49 boys and 60 girls) in one of the residential complexes in the first zone of Tehran. After obtaining official permits from the Education Office, two of four available governmental elementary schools in the zone were randomly selected. One school exclusive for girls $(n=60)$ and one school exclusive for boys $(n=49)$ were selected, and their students were randomly divided into the case group and the control group.

Instrument: The School Anxiety Scale-Teacher Report (SAS-TR) was filled out by their teachers. SAS-TR was designed by Lyneham et al. (2008) with 16 questions about children's behavior at school in the past 3 to 6 months. This questionnaire takes at least 5 minutes to complete, so teachers cooperated well. A 4-point Likert-type scale was used to rate the items, from 0 (never) to 3 (always). This scale has two subscales: social an- 
xiety and general anxiety. A cutting point of 10 indicates high for general anxiety, and a cutting point of 8 indicates high for social anxiety.

The questionnaire was validated based on the World Health Organization recommendation of reverse translation through face and content validity. Three psychiatrists, several lecturers, and teachers evaluated the questionnaire to improve the face validity. Their recommendations were applied, showing that the questionnaire is capable of evaluating the level of anxiety in students. Exploratory factor analysis, main components, and varimax rotation were used to validate construct validity. The reliability of SAS-TR was assessed and Cronbach's alpha coefficient for the Iranian SAS-TR was 0.92 and interclass correlation coefficient (ICC) was found to be 0.81 (Hajiamini et al., 2012).

The level of mothers' communication skills was measured using the Queendom Communication Skill Questionnaire. Queendom designed this questionnaire in 2004 to assess adult's communication skills using 34 statements that describe communication skills. The responder should read and rate each statement, based on the degree that each statement applies to him or her, on a 5-point Likert-type scale, from 1 (never) to 5 (always). Communication skill subscales include listening, receiving, and sending message, vision to communication process, excitement control, and communication with certainty. The total score for each individual out of 34 statements shows his or her communication skills. The score can range from 34 to 170. Some of the statements are reversely scored because of their content (Queendom, 2004).

The reliability of this questionnaire was measured by Hussein Chary and Fadakar (2005) using factor analysis. Its validity was measured as 0.71 and 0.69 in a sample of 733 school students and university students, respectively. Furthermore, Yousefi (2006) found the reliability of this questionnaire as 0.81 using Cronbach's alpha and as 0.77 using split half validity.

Procedure: Afterward, a meeting was arranged with the help of school principals to give the multimedia CD to mothers in the case group and to discuss how to use the software. Then they were given 2 weeks to study the software and contact the researcher by phone if needed. Students' anxiety and mothers' communication skills were evaluated again after 2 months.

The multimedia software program was selected from three important multimedia programs: Flash, Builder and Autorun (version 7.5). The original software with eight supplementary programs and eight series of effects was purchased. An important technical point in this project is the 58-GB backup in 14 versions that were copied on a DVD. The validity of this software program was assessed by several experts.

Data were analyzed by chi-square, paired, and independent $t$ tests using the Statistical Package for the Social Sciences (Version 16; SPSS Inc., Chicago, IL, USA). $P<0.05$ was considered significant. In this study, the information in the questionnaires was kept confidential and was not recorded in students' files. The educational multimedia software was given to the control group after the posttest.

\section{Results}

In this study, 109 first-grade students (55\% girls and $45 \%$ boys) were enrolled; most were good or excellent at school (78\%) and were socioeconomically well-off (57.8\%). The anxiety level of students before intervention was $17.9 \%, 15.7 \%$, and $16.1 \%$ in social anxiety, general anxiety, and total anxiety, respectively (Table 1).

As seen in Table 2, the mean (SD) score of the communication skills of mothers was (114 \pm 9.8 ) before intervention, which significantly improved after intervention in the case group $(P<0.05)$ (Table 2).

Moreover, the Man-Whitney statistical test showed no significant difference between the multimedia and the control groups, whereas the Wilcoxon test showed that results in the multimedia group were significantly different after intervention $(P=0.01)$. However, the difference was not significant in the control group (Table 3 ).

\section{Discussion}

Children's anxiety can sometimes turn to a predicament if disregarded by family, school, or even the society and can lead to complications in adulthood. Therefore, early diagnosis and treatment is highly important (Muris et al., 2003). This study aimed to assess the effect of the communication skills training of mothers using multimedia software program in reducing the anxiety level of first-grade students in a residential complex in Tehran.

Communication skills of mothers were average before intervention but increased significantly after training $(P<0.05)$. Although no similar studies are found, the advantage of using multimedia for training over other educational modes has been proven in several studies, including the on-the-job training of teachers, the learning 
Table 1. Absolute and relative frequency of anxiety in students before intervention, based on sex.

\begin{tabular}{ccccccc}
\hline & \multicolumn{2}{c}{ Social } & \multicolumn{2}{c}{ General } & \multicolumn{2}{c}{ Total } \\
\cline { 2 - 7 } $\begin{array}{c}\text { Subscale } \\
\text { sex }\end{array}$ & Normal & High & Normal & High & Normal & High \\
\cline { 2 - 7 } & $\mathrm{N}(\%)$ & $\mathrm{N}(\%)$ & $\mathrm{N}(\%)$ & $\mathrm{N}(\%)$ & $\mathrm{N}(\%)$ & $\mathrm{N}(\%)$ \\
\hline Girl & $116(90.6)$ & $12(9.4)$ & $120(93.8)$ & $8(6.2)$ & $121(94.5)$ & $7(5.5)$ \\
Boy & $67(70.5)$ & $28(29.5)$ & $68(71.6)$ & $27(28.4)$ & $66(69.5)$ & $29(30.5)$ \\
Total & $183(82.1)$ & $40(17.9)$ & $188(84.3)$ & $35(15.7)$ & $187(83.9)$ & $36(16.1)$ \\
\hline
\end{tabular}

Table 2. Absolute and relative frequency of mothers’ communication skills before and after intervention.

\begin{tabular}{cccc}
\hline $\begin{array}{c}\text { Stage } \\
\text { group }\end{array}$ & Before & After & $\begin{array}{c}\text { Paired T-test } \\
\text { significant level }\end{array}$ \\
\cline { 2 - 4 } Multimedia & Mean $( \pm$ SD) & Mean $( \pm$ SD) & 0.001 \\
Control & $114.16( \pm 9.8)$ & $122.97( \pm 7.07)$ & 0.08 \\
\hline T-independent significant level & $116.4( \pm 10.78)$ & $119.22( \pm 8.92)$ & 0.01 \\
\hline
\end{tabular}

Table 3. Comparison of total anxiety of students in the multimedia group with the case before and after intervention.

\begin{tabular}{cccc} 
Stage & Before & After & $\begin{array}{c}\text { Wilcoxon } \\
\text { significant level }\end{array}$ \\
\cline { 2 - 3 } Multimedia & Mean $( \pm \mathrm{SD})$ & Mean $( \pm \mathrm{SD})$ & $<0.001$ \\
Control & $8.52( \pm 9.55)$ & $6.33( \pm 7.66)$ & $>0.9$ \\
\hline Mann-Whitney significant level & $7.98( \pm 8.65)$ & $7.99( \pm 8.79)$ & 0.26 \\
\hline
\end{tabular}

of nursing students, or the knowledge score of examinees. They all proved that multimedia training is more effective than other types of training (Pryor \& Bitter, 2008; Atashzadeh et al., 2006; Mladenovski \& Kieser, 2008). These findings are in line with those of the present study, indicating the elevation of mothers' communication skills.

The results showed that students' level of anxiety decreased significantly after intervention, that is, the communication skills training of mothers using multimedia software program. No studies on the effect of teaching communication skills to mothers to reduce students' anxiety are found. However, similar studies have shown the effect of communication skills training in other fields, including Drysdale et al. (2008), who showed the effect of communication skills training on IQ problems in children of 9 to 11 years old. Furthermore, Mahmoudi Rad (2007) studied communication skills and social problem solving on self-esteem and IQ of third-grade students in Tehran. They showed its effectiveness. Another study by Barmkuhy (2009) proved the efficacy of life skills training on reducing depression symptoms in third-grade middle school female students of Qazvin city. The results showed the effect of these skills in reducing depression symptoms and psychological problems. All these findings are compatible with ours. On the contrary, Gadomski et al. (2010) studied the effect of communication skills training to mental health professionals and its effect on children (5 - 16 years old) receiving primary care (screening mental health problems). They did not find a significant difference between the case and the control groups for the frequency and continuity of their visits. This finding does not agree with our results. This difference might be explained in that mothers have a more important role than healthcare personnel on children's anxiety level. Another reason might be the research environment. Healthcare centers can be stressful, which can justify the lack of decrease in the anxiety levels in children. However, in our study, mothers were trained, and students did not receive any additional stress. This finding requires more extensive studies.

\section{Restrictions}

One of the restrictions of this study was the fact that we could not access mothers' names and telephone num- 
bers. Hence, we could not compare their individual communication skills before and after intervention, and we had to compare mean and standard deviation in the case group before and after intervention.

Therefore, a more extensive study should be designed for other regions and teachers' communication skills should be studied after training using this software program.

\section{Conclusion}

The communication skills training of mothers through multimedia software programs reduces children's anxiety. Therefore, considering the frequency of separation anxiety and even social anxiety in children, especially firstgrade students, it is essential to train mothers' communication skills to control and reduce such anxiety. Because most mothers are busy and cannot attend classes and that this method of training is cost-effective and can be used repeatedly, the expansion of virtual training is recommended.

\section{References}

Abadi, S. R. S., \& Tavakoli, M. (2005). Review the Status of Visual Material—Listening Central Libraries of Iranian Public Universities. New Thoughts on Education, 1, 71-88.

Atashzadeh, F., Ghezelbash, A., \& Abdolrahimi, M. (2006). Compare Learning Using Lecture (Teacher Axial) and Problem Solving Methods in Computer Tutorial with Bachelor Students of Shahid Beheshti University. Journal of Yazd University Medical Science, 11, 86-193.

Barmkuhy, A. A. (2009). Life Skills Training to Reduce Depression. Iranian Psychologists, 297-306.

Broeren, S., \& Muris, P. (2008). Psychometric Evaluation of Two New Parent-Rating Scales for Measuring Anxiety Symptoms in Young Dutch Children. Journal of Anxiety Disorders, 22, 949-958.

http://dx.doi.org/10.1016/j.janxdis.2007.09.008

Brückl, T. M., Wittchen, H. U., Höfler, M., Pfister, H., Schneider, S., \& Lieb, R. (2007). Childhood Separation Anxiety and the Risk of Subsequent Psychopathology: Results from a Community Study. Psychotherapy and Psychosomatics, 76, 4756. http://dx.doi.org/10.1159/000096364

Cartwright-Hatton, S., Mcnicol, K., \& Doubleday, E. (2006). Anxiety in a Neglected Population: Prevalence of Anxiety Disorders in Pre-Adolescent Children. Clinical Psychology Review, 26, 817-833. http://dx.doi.org/10.1016/j.cpr.2005.12.002

Craske, M. G., Waters, A. M., Lindsey Bergman, R., Naliboff, B., Lipp, O. V., Negoro, H., \& Ornitz, E. M. (2008). Is Aversive Learning a Marker of Risk for Anxiety Disorders in Children? Behaviour Research and Therapy, 46, 954-967. http://dx.doi.org/10.1016/j.brat.2008.04.011

Dehkordi, A. H., Delaram, M., Safdari, F., Tali, S. S., Nia, A. M. H., \& Al, A. E. (2008). Comparison of Speech and Self Awareness of Parents of Children with Thalassemia Major on How to Care for Their Children. Journal of Shahrekord University Medical Sciences, 10, 52-58.

Drysdale, J., Casey, J., \& Porter-Armstrong, A. (2008). Effectiveness of Training on the Community Skills of Children with Intellectual Disabilities. Scandinavian Journal of Occupational Therapy, 15, 247-255.

Dubi, K., \& Schneider, S. (2009). The Picture Anxiety Test (PAT): A New Pictorial Assessment of Anxiety Symptoms in Young Children. Journal of Anxiety Disorders, 23, 1148-1157. http://dx.doi.org/10.1016/j.janxdis.2009.07.020

Gadomski, A., Wissow, L. S., Slade, E., \& Jenkins, P. (2010). Training Clinicians in Mental Health Communication Skills: Impact on Primary Care Utilization. Academic Pediatrics, 10, 346-352. http://dx.doi.org/10.1016/j.acap.2010.06.012

Gar, N. S., \& Hudson, J. L. (2008). An Examination of the Interactions between Mothers and Children with Anxiety Disorders. Behaviour Research and Therapy, 46, 1266-1274. http://dx.doi.org/10.1016/j.brat.2008.08.006

Ghaemi, A. (2007). Mother's Role in Education. Tehran: Amiri.

Hajiamini, Z., Mohamadi, A., Ebadi, A., Fathi-Ashtiani, A., Tavousi, M., \& Montazeri, M. (2012). The School Anxiety Scale-Teacher Report (SAS-TR): Translation and Psychometric Properties of the Iranian Version. BMC Psychiatry, 12, 82. http://dx.doi.org/10.1186/1471-244X-12-82

Hope, A., Hill, S. M., \& Edvard, K. (2004). Increase Self Esteem in Children and Adolescents. Tehran.

Hussein Chary, M., \& Fadakar, M.M. (2005). The Effect of University on Communication Skills Based on the Comparison Students. Behavior Daneshvar Journal, 15, 21-32.

Kendall, P. C., Puliafico, A. C., Barmish, A. J., Choudhury, M. S., Henin, A., \& Treadwell, K. S. (2007). Assessing Anxiety with the Child Behavior Checklist and the Teacher Report form. Journal of Anxiety Disorders, 21, 1004-1015. http://dx.doi.org/10.1016/j.janxdis.2006.10.012

Kessler, R. C., Berglund, P., Demler, O., Jin, R., Merikangas, K. R., \& Walters, E. E. (2005). Lifetime Prevalence and Age- 
of-Onset Distributions of DSM-IV Disorders in the National Comorbidity Survey Replication. JAMA Psychiatry, 62, 593602. http://dx.doi.org/10.1001/archpsyc.62.6.593

Khalylan, A., Hassanzadeh, R., \& Zarghami, M. (2000). Relationship between School Stress Factors and Somatic Complaints in Students of Sari City in the Year 79-1378. Journal-Mazandaran University of Medical Sciences, 10, 79-84.

Li, H. C. W., \& Lopez, V. (2007). Development and Validation of a Short form of the Chinese Version of the State Anxiety Scale for Children. International Journal of Nursing Studies, 44, 566-573. http://dx.doi.org/10.1016/j.ijnurstu.2005.12.004

Lyneham, H. J., Street, A. K., Abbott, M. J., \& Rapee, R. M. (2008). Psychometric Properties of the School Anxiety ScaleTeacher Report (SAS-TR). Journal of Anxiety Disorders, 22, 292-300. http://dx.doi.org/10.1016/j.janxdis.2007.02.001

Mahmoudi Rad, M., Arasteh, H.R., \& Afqh, S. (2007). Century Barati. The Role of Communication Skills and Social Problem Solving of Self-Esteem and IQ Third Grade Students. Journal of Rehabilitation, 29, 69-73.

Mladenovski, A., \& Kieser, J. (2008). The Efficacy of Multimedia Pre-Operative Information for Patients: A Pilot Study. The New Zealand Dental Journal, 104, 36-43.

Muris, P. (2007). Normal and Abnormal Fear and Anxiety in Children and Adolescents. Amsterdam: Elsevier Science.

Muris, P., Meesters, C., Mayer, B., Bogie, N., Luijten, M., Geebelen, E., Bessems, J., \& Smit, C. (2003). The Koala Fear Questionnaire: A Standardized Self-Report Scale for Assessing Fears and Fearfulness in Pre-School and Primary School Children. Behaviour Research and Therapy, 41, 597-617. http://dx.doi.org/10.1016/S0005-7967(02)00098-0

Pryor, C. R., \& Bitter, G. G. (2008). Using Multimedia to Teach Inservice Teachers: Impacts on Learning, Application, and Retention. Computers in Human Behavior, 24, 2668-2681. http://dx.doi.org/10.1016/j.chb.2008.03.007

Queendom (2004). Communication Skills Test-Revise. http://www.queendom.com/cgi-bin/transfer.cgi

Seyyed, R. P., Habibullahi, S., \& Faramarzi, S. (2010). Effectiveness of Life Skills Education Program on Adjustment of Blind and Low Vision Students. Journal of Educational Strategies, 3, 7-11.

Waters, A. M., Craske, M. G., Bergman, R. L., Naliboff, B. D., Negoro, H., \& Ornitz, E. M. (2008). Developmental Changes in Startle Reactivity in School-Age Children at Risk for and with Actual Anxiety Disorder. International Journal of Psychophysiology, 70, 158-164. http://dx.doi.org/10.1016/j.ijpsycho.2008.07.014

Whiteside, S. P., \& Brown, A. M. (2008). Exploring the Utility of the Spence Children’s Anxiety Scales Parent- and ChildReport Forms in a North American Sample. Journal of Anxiety Disorders, 22, 1440-1446. http://dx.doi.org/10.1016/j.janxdis.2008.02.006

Yousefi, F. (2006). Relationship between Emotional Intelligence and Communication Skills in Students. Iranian Psychologists, 3, 123-135.

Zolfaghari, M., Mehrdad, N., Yekta, Z. P., Barughi, N. S., \& Bohrani, N. (2007). The Effect of Two Methods of Lecture and E-Learning Training on Learning Mother and Child Health Course of Nursing Students. Iranian Journal of Medical Education, 7, 31-39. 